\title{
The effect of dietary oils and $\alpha$-tocopherol on the n-3 fatty acid content and oxidative stability of broiler meat
}

\author{
Y. X. Huang and E. L. Miller \\ Department of Clinical Veterinary Medicine, University of Cambridge, Cambridge CB3 OES
}

\section{Introduction}

The benefits to man of an increased consumption of n-3 fatty acids, especially eicosapentaenoic acid (EPA) and docosahexaenoic acid (DHA) and of maintaining an optimal ratio of $\mathbf{n}-6: \mathrm{n}-3$ fatty acids in the diet on neural development of the foetus and neonate, incidence of coronary heart disease (CHD), death rate from CHD, inflammatory conditions e.g. psoriasis, rheumatoid arthritis, systemic lupus erythematosus, and suppression of cancer cell growth have recently been reviewed and recognized (British Nutrition Foundation (BNF), 1992). This report recommends a doubling in dietary intake of $n$ 3 fatty acids to $1.5 \%$ of energy, primarily obtained by consumption of fish. However, not everyone would wish to eat the equivalent of a 100 to $120 \mathrm{~g}$ portion of salmon two to three times a week. Inclusion of fish oil in a broiler chicken diet will incorporate EPA and DHA into broiler meat and could make a significant contribution to the recommended intakes of these fatty acids by man (Hulan, Ackman, Ratnayake and Proudfoot, 1988). An enhanced intake of antioxidant vitamins ( $\beta$-carotene, ascorbic acid and $\alpha$-tocopherol) is also considered protective against CHD (Department of Health, 1991). In addition, feeding chickens a diet containing fish oil or $\alpha$-tocopherol significantly increases antibody production and potentially increases their resistance to disease (Nockels, 1986; Fritsche, Cassity and Shu-Cai Huang, 1991). However, the use of fish oil in an animal diet is limited by its oxidative instability and the risk of causing taint in the meat (Opstvedt, 1984). The purpose of this experiment was to investigate the feasibility of increasing the content of EPA and DHA in broiler meat without compromising oxidative stability by feeding refined fish oil together with supra-nutritional amounts of $\alpha$-tocopherol.

\section{Material and methods}

Twenty day-old ROSS cockerels were allocated to each of nine experimental diets, according to a factorial combination of three $\mathrm{DL}-\alpha$-tocopherol acetate levels (50, 250 and 450 i.u. per $\mathrm{kg}$ ) with three fish oil (FO, MaxEPA) levels $(0 \mathrm{~g} F+10 \mathrm{~g}$ soya oil $+40 \mathrm{~g}$ lard, $10 \mathrm{~g}$ FO $+40 \mathrm{~g}$ lard, $20 \mathrm{~g} \mathrm{FO}+30 \mathrm{~g}$ lard per $\mathrm{kg}$ diet). At 52 days, birds were commercially slaughtered. $\alpha$-tocopherol and fatty acid profiles were analysed in breast and thigh muscles by high performance liquid chromatography (Ueda and Igarashi, 1990) and gas-liquid chromatography, respectively. Thiobarbituric acid reactive substances (TBARS) (Crackel, Gray, Booren and Buckley, 1988) were measured in uncooked meat $24 \mathrm{~h}$ post mortem and again after 6 days under refrigeration. Chickens were plain roasted and breast and thigh meat were assessed by a taste panel immediately after cooking and again after refrigerated storage at -3 to $0^{\circ} \mathrm{C}$ of the cooked half carcass for 3 days. TBARS were determined on freshly cooked breast and thigh meat and again after 3 and 8 days of refrigerated storage. Further chickens were stored for 6 months at -20 to $-25^{\circ} \mathrm{C}$, then cooked and subjected to the same taste panel and TBARS assessment immediately after cooking and after further refrigerated storage of the cooked meat.

\section{Results}

The first increment of FO substantially increased n-3 fatty acid content of meat lipids at the expense of n-6 acids and without change in the proportion of saturated or monounsaturated fatty acids (Table 1).

The change was greater with breast muscle than with thigh muscle. The second increment of FO further increased the n-3 content of thigh muscle lipids but brought about only a small further increment in breast muscle lipids.

Tissue $\alpha$-tocopherol was highly correlated $(P<0.01)$ with dietary $\alpha$-tocopherol concentration (breast muscle $r=0917$; thigh muscle $r=0.843$ ) and was reduced by FO $(P<0 \cdot 05)$. Thigh muscle contained almost twice as much as breast muscle at each dietary level of $\alpha$-tocopherol (Figure 1).

TBARS of all fresh or uncooked refrigerated meat were low and within an acceptable range (data not shown). Inclusion of FO without additional vitamin E increased TBARS development during cooking and subsequent refrigerated storage in a dose related 
Table 1 Fatty acids composition (\% lipid) of breast and thigh muscles of broiler given different levels dietary fish oil

\begin{tabular}{|c|c|c|c|c|c|c|c|}
\hline \multirow{3}{*}{$\begin{array}{l}\text { Meat } \\
\text { type }\end{array}$} & \multirow{3}{*}{$\begin{array}{l}\text { Fatty } \\
\text { acids }\end{array}$} & \multicolumn{6}{|c|}{ Dietary fish oil $(\mathrm{g} / \mathrm{kg})$} \\
\hline & & \multicolumn{2}{|c|}{0} & \multicolumn{2}{|c|}{10} & \multicolumn{2}{|c|}{20} \\
\hline & & Mean & s.e. & Mean & s.e. & Mean & s.e. \\
\hline \multirow{3}{*}{ Breast } & Saturatedt & $35.7^{\mathrm{b}}$ & 0.65 & $37 \cdot 0^{\mathrm{ab}}$ & 0.78 & $39 \cdot 6^{a \star}$ & $1 \cdot 36$ \\
\hline & $n-3$ & $2 \cdot 4^{\mathrm{b}}$ & $0 \cdot 47$ & $9 \cdot 2^{\mathrm{a}}$ & $1 \cdot 07$ & $10 \cdot 9^{\mathrm{a}}$ & 0.58 \\
\hline & $n-6$ & $20 \cdot 5^{\mathrm{b}}$ & 0.58 & $14 \cdot 2^{\mathrm{a}}$ & 0.29 & $14 \cdot 04^{\text {a }}$ & 0.56 \\
\hline \multirow{5}{*}{ Thigh } & Others $^{2}$ & $35 \cdot 3$ & 1.51 & $33 \cdot 8$ & 1.88 & $34 \cdot 2$ & $2 \cdot 632$ \\
\hline & Saturated $\neq$ & 33.5 & 0.58 & 34.9 & 0.49 & $34 \cdot 8$ & 0.62 \\
\hline & $n-3$ & $1.4^{\mathrm{c}}$ & 0.20 & $5 \cdot 1^{b}$ & 0.61 & $7 \cdot 7^{\mathrm{a}}$ & 0.58 \\
\hline & $n-6$ & $20 \cdot 2^{b}$ & 0.74 & $15 \cdot 7^{a}$ & 0.33 & $15 \cdot 5^{\mathrm{a}}$ & 0.50 \\
\hline & Others $^{2}$ & $38 \cdot 6$ & $1 \cdot 23$ & $38 \cdot 3$ & $1 \cdot 11$ & 35.9 & 1.47 \\
\hline
\end{tabular}

$+15: 0$ and shorter chain saturated fatty acids not included

$\ddagger$ All other mono- or poly-unsaturated fatty acids exclusive of $n-3$ and $n-6$

$a, b, c$, Tested by $t$ test, without labels or labelled with the same letter in the same line means no significant difference; $a$, $b$ and c: significant difference at 0.01 level; $a^{\star}, b^{\star}, c^{\star}$ at 0.05 level. (Mean of six).

manner. Additional $\alpha$-tocopherol at 250 i.u. per $\mathrm{kg}$ reduced oxidation during cooking and subsequent storage of cooked breast and thigh meat from treatments both without and with added FO. After 3 days of refrigerated storage, cooked thigh meat had consistently greater TBARS than breast meat across all treatments (data not shown). When cooked after 6 months frozen storage, TBARS were only slightly, and not significantly, increased over those for freshly cooked meat. During subsequent refrigerated storage, TBARS increased in a similar pattern, but with slightly enhanced values, as with fresh meat and the changes were further exaggerated after 8 days refrigerated storage (Figures 2 and 3 ).

When tasted immediately after cooking, meat from all treatments was acceptable whether fresh or after 6

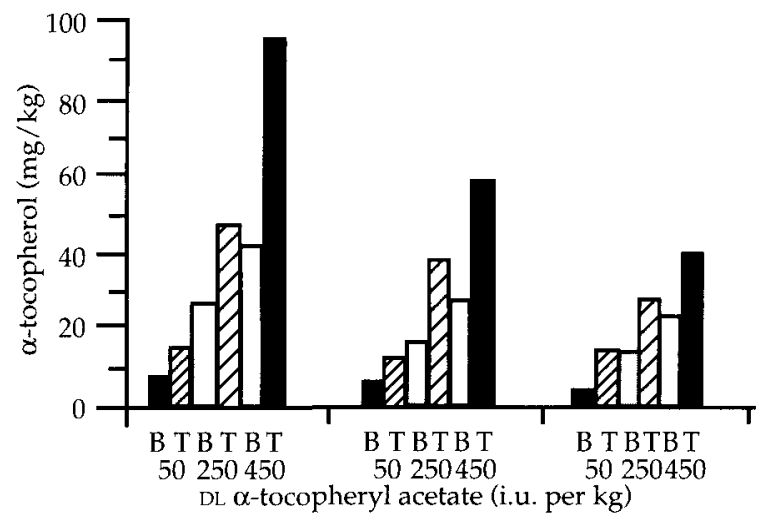

Fish oil $(\mathrm{g} / \mathrm{kg})$

$$
-0-10-20-
$$

Figure 1 Alpha-tocopherol in fresh breast and thigh muscle.

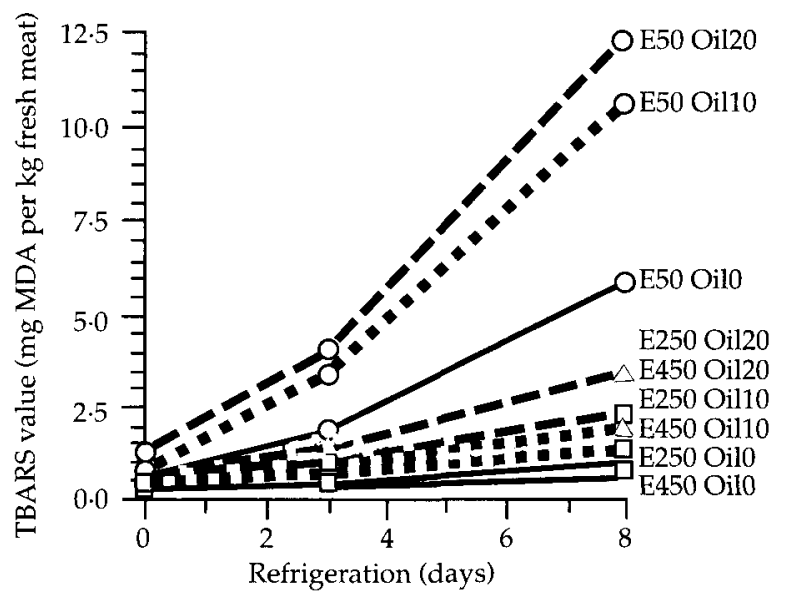

Figure 2 TBARS development of cooked breast muscle during refrigeration at $-3^{\circ} \mathrm{C}$ to $0^{\circ} \mathrm{C}$. E50 means dietary $\alpha$-tocopherol 50 i.u. per $\mathrm{kg}$. Oil20 means dietary fish oil $20 \mathrm{~g} / \mathrm{kg}$.

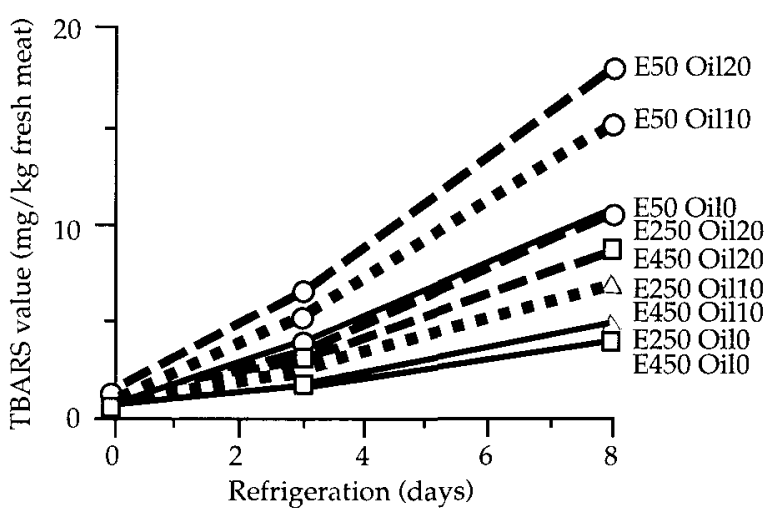

Figure 3 TBARS development of cooked thigh meat during refrigeration at $-3{ }^{\circ} \mathrm{C}$ to $0^{\circ} \mathrm{C}$. E50 means dietary $\alpha$-tocopherol 50 i.u. per $\mathrm{kg}$. Oil 20 means dietary fish oil $20 \mathrm{~g} / \mathrm{kg}$. 
Table 2 The adjusted mean scorest of taste panel assessment on dark meat refrigerated for 3 days after cooking $\ddagger$

\begin{tabular}{|c|c|c|c|c|c|c|c|}
\hline \multicolumn{2}{|c|}{ Treatment } & \multicolumn{3}{|c|}{ Fresh§ } & \multicolumn{3}{|c|}{ Frozen§ } \\
\hline $\begin{array}{c}\alpha-t \\
(\mathrm{iu} / \mathrm{kg})\end{array}$ & $\begin{array}{c}\mathrm{FO} \\
(\mathrm{g} / \mathrm{kg})\end{array}$ & Odour & Taste & Score $\|$ & Odour & Taste & Score \\
\hline 50 & 0 & $2 \cdot 8$ & $2 \cdot 9^{a}$ & $3 \cdot 8^{\mathrm{ab}}$ & $6 \cdot 4^{a}$ & $6 \cdot 5^{\mathrm{ab}}$ & $6 \cdot 6^{a}$ \\
\hline 250 & 0 & $2 \cdot 6$ & $3 \cdot 0^{\mathrm{a}}$ & $4 \cdot 0^{\mathrm{ab}}$ & $4 \cdot 9^{d c}$ & $5 \cdot 3^{\mathrm{cbde}}$ & $5 \cdot 5^{\mathrm{abc}}$ \\
\hline 450 & 0 & 2.6 & $2 \cdot 7^{a}$ & $3 \cdot 6^{\mathrm{ab}}$ & $5 \cdot 8^{a b c}$ & $6 \cdot 1^{\mathrm{abc}}$ & $6 \cdot 4^{\mathrm{ab}}$ \\
\hline 50 & 10 & $2 \cdot 5$ & $2 \cdot 9^{a}$ & $4 \cdot 2^{\mathrm{a}}$ & $5 \cdot 0^{\mathrm{dc}}$ & $5 \cdot 5^{\mathrm{abcd}}$ & $5 \cdot 6^{a b c}$ \\
\hline 250 & 10 & 2.7 & $2 \cdot 7^{a}$ & $4 \cdot 0^{\mathrm{ab}}$ & $6 \cdot 0^{\mathrm{ab}}$ & $5 \cdot 9^{a b c}$ & $6 \cdot 3^{\mathrm{ab}}$ \\
\hline 450 & 10 & $2 \cdot 3$ & $2 \cdot 5^{\mathrm{a}}$ & $3 \cdot 3^{b c}$ & $6 \cdot 0^{a b}$ & $6 \cdot 6^{\mathrm{a}}$ & $6 \cdot 8^{a}$ \\
\hline 50 & 20 & $2 \cdot 3$ & $1.9^{b}$ & $3 \cdot 1^{\mathrm{c}}$ & $4 \cdot 6^{\mathrm{d}}$ & $4 \cdot 4^{e}$ & $4 \cdot 7^{c}$ \\
\hline 250 & 20 & 2.5 & $2 \cdot 8^{\mathrm{a}}$ & $4 \cdot 1^{\mathrm{a}}$ & $5 \cdot 4^{\mathrm{bcd}}$ & $5 \cdot 0^{\text {cde }}$ & $4.7^{c}$ \\
\hline 450 & 20 & 2.5 & $2 \cdot 6^{\mathrm{a}}$ & $3 \cdot 8^{\mathrm{ab}}$ & $5 \cdot 1^{\mathrm{bcd}}$ & $4 \cdot 5^{\text {de }}$ & $5 \cdot 1^{a b c}$ \\
\hline
\end{tabular}

$a, b, c, d$ The different letter at the same column means significant difference $(P<0 \cdot 05)$, otherwise no significant difference.

+ Treatment means adjusted for block effect.

$¥$ The scores of breast meat and thigh meat tasted immediately after cooking are not presented here.

$\S$ Fresh meat: scored on a scale of 1 to 3 for odour and taste $(2=$ acceptable), 1 to 5 for overall acceptability $(3=$ acceptable); frozen meat: after 6 months freezing store, all scores are a scale of 1 to $10(5=$ acceptable $)$.

II Score overall acceptability.

months frozen storage. No consistent effects of FO or $\alpha$-tocopherol on FO flavour scores were observed (data not shown). After 3 days refrigerated storage of fresh cooked meat, thigh meat from 50 i.u. $\alpha$-tocopherol with $20 \mathrm{~g} / \mathrm{kg}$ FO was only marginally acceptable but additonal $\alpha$-tocopherol, at 250 or 450 i.u. significantly improved acceptability $(P<0.05)$, (Table 2).

With the frozen meat, after 3 days refrigerated storage, thigh meat from 50 i.u. $\alpha$-tocopherol with $20 \mathrm{~g} / \mathrm{kg}$ FO was definitely not acceptable and additional $\alpha$-tocopherol at 250 or 450 i.u. only increased two-thirds of the assessments to marginally acceptable. Breast meat from birds given 10 or $20 \mathrm{~g} / \mathrm{kg}$ FO and thigh meat from those given $10 \mathrm{~g} / \mathrm{kg}$ FO were still acceptable after 3 days refrigerated storage irrespective of dietary $\alpha$-tocopherol.

\section{Discussion}

Replacement of $10 \mathrm{~g} / \mathrm{kg}$ soya-bean oil with FO reduced the $n-6: n-3$ ratio from $8.5: 1$ to $1.5: 1$ in breast meat and $14: 1$ to $1: 1$ in thigh meat. Further addition of $F O$ at the expense of lard decreased the ratios to $1 \cdot 3: 1$ and $2: 1$ respectively. Thus, inclusion of FO in the broiler diet substantially improves the $\mathbf{n}$ $6: n-3$ ratio of the meat towards the optimum of $4: 1$ recommended for the whole diet (BNF, 1992). Supplementation with 250 i.u. per $\mathrm{kg}$ or more $\alpha$ tocopherol resulted in substantially greater tissue levels of $\alpha$-tocopherol than have been reported previously, presumably due to the cumulative effect of feeding relatively high levels from day old. The greater deposition of $\alpha$-tocopherol in thigh than breast muscle confirms earlier reports with chickens (Lin, Gray, Ashgar, Buckley, Booren and Flegel, 1989) and turkeys (Uebersax, Dawson and Uebersax, 1978, Sheldon, 1984) and appears to relate to anatomical (more lipid, more mitochondria and microsomes in thigh muscle) and physiological (greater oxidative metabolism in thigh muscle) differences. Replacing soya-bean oil with FO reduced tissue $\alpha$-tocopherol suggesting increased utilization of $\alpha$-tocopherol to stabilize the FO fatty acids. TBARS have previously been shown to increase during cooking and subsequent chill storage of chicken meat from birds given vegetable oils. Addition of $\alpha$ tocopherol, at 200 i.u. per $\mathrm{kg}$ has minimized these changes (Lin et al., 1989). These observations have now been extended to show that 250 i.u. per $\mathrm{kg} \alpha-$ tocopherol or more will stabilize chicken meat containing high levels of the more reactive EPA and DHA as judged by TBARS and taste panel assessment.

\section{Conclusion}

Ten or $20 \mathrm{~g} / \mathrm{kg}$ inclusion of fish oil in a broiler diet with supplementation of 250 i.u. per $\mathrm{kg}$ or more $\alpha$-tocopherol can produce meat with a high $n-3$ fatty acid content with a significantly improved ratio of $n-3: n-6$ and meat keeping quality without significantly reducing meat flavour.

\section{Acknowledgements}

Financial support from Cambridge Overseas Trust, F. Hoffman-La Roche AG, United Fish Products Ltd and Master Farm Nutrition made this study possible and is gratefully acknowledged. Generous donations of MaxEPA 
from Seven Seas Ltd and broiler chickens from Sovereign Chicken Ltd are also acknowledged. We thank the catering staff of Girton College for their invaluable assistance in cooking the chickens, assisting with taste panel assessment and providing deep frozen and refrigerated storage of the chickens.

\section{References}

British Nutrition Foundation. 1992. Unsaturated fatty acids : nutritional and physiological significance. Report of the British Nutrition Foundation's Task Force. Chapman and Hall, London.

Crackel, R. L., Gray, J. I. Booren, A. M. and Buckley, D. J. 1988. Some further observations on the TBA test as an index of lipid oxidation in meats. Food Chemistry 28: 187-196.

Department of Health. 1991. Dietary reference values for food energy and nutrients for the United Kingdom, Report on health and social subjects, no 41. Her Majesty's Stationery Office, London.

Fritsche, K. L., Cassity, N. A. and Shu-Cai Huang. 1991. Effect of dietary fat source on antibody production and lymphocyte proliferation in chickens. Poultry Science 70: 611-617.
Hulan, H. W., Ackman, R. G. Ratnayake, W. M. N. and Proudfoot, F. G. 1988. Omega-3 fatty acid levels and performance of broiler chickens fed redfish meal or redfish oil. Canadian Journal of Animal Science 68: 533-547.

Lin, C. F., Gray, J. L., Ashgar, A., Buckley, D. J., Booren, A. M. and Flegel, C. J. 1989. Effects of dietary oils and tocopherol supplementation on lipid composition and stability of broiler meat. Journal of Food Science 54: 1457-1460.

Nockels, C. F. 1986. Nutrient modulation of the immune system. In Recent adoances in animal nutrition -1986 (ed. W. Haresign and D. J. A. Cole), pp. 177-192. Butterworths, London.

Opstvedt, J. 1984. Fish fats. In Fats in animal nutrition (ed. J. Wiseman), pp. 53-82. Butterworths, London.

Sheldon, B. W. 1984. Effect of dietary tocopherol on the oxidative stability of turkey meat. Poultry Science 63: 673-681.

Uebersax, M. A., Dawson, L. E. and Uebersax, K. L. 1978. Storage stability (TBA) of meat obtained from turkeys receiving tocopherol supplementation. Poultry Science 57: 937-946.

Ueda, T. and Igarashi, O. 1990. Determination of Vitamin E in biological specimens and foods by HPLC. Pretreatment of samples and extraction of tocopherol. Journal of Micronutrient Analysis. 7: 79-96. 